\title{
Editorial: New Technologies for Investigating Microstructures and Enhancing Performance of Cementitious Materials
}

\author{
Lei Wang ${ }^{1,2 *}$, E. Chen ${ }^{3 *}$, Shaoqin Ruan ${ }^{4}$ and Shengwen Tang ${ }^{5 *}$ \\ ${ }^{1}$ College of Urban Construction, Wuchang University of Technology, Wuhan, China, ${ }^{2}$ College of Materials Science and \\ Engineering, Xi'an University of Architecture and Technology, Xi'an, China, ${ }^{3}$ Division of Structural Engineering, Chalmers \\ University of Technology, Göteborg, Sweden, ${ }^{4}$ College of Civil Engineering and Architecture, Zhejiang University, Hangzhou, \\ China, ${ }^{5}$ State Key Laboratory of Water Resources and Hydropower Engineering Science, Wuhan, China
}

Keywords: cementitious material, technologies, microstructure, performance, experimental techniques

Editorial on the Research Topic

New Technologies for Investigating Microstructures and Enhancing Performance of Cementitious Materials

\section{INTRODUCTION}

Cementitious material, including Portland cement concrete, polymer cement-based composites, etc., are highly complex in phase compositions. The increase in demand for high-performance cementitious material in recent years has resulted in renewed interest in the study of the new technologies for investigating microstructures and enhancing performance of cementitious materials.

Development of advanced and effective experimental techniques during the last decade, such as X-ray diffraction(XRD) (Ruan and Unluer, 2017), thermogravimetry analysis (TG) (Lv et al., 2020), scanning electron microscopy (SEM) (Wang et al., 2021a), infrared spectroscopy (IR) (Hou et al., 2020; Li et al., 2021), air void analyzer (Wang et al., 2021b), nanoindentation (Lv et al., 2021), mercury intrusion porosimetry (MIP) (Wang et al., 2021c), and nuclear magnetic resonance (NMR) (Wang et al., 2020), has revealed that the micro-scale properties of materials have a significant effect on their macro-scale properties. However, traditional technologies have not been able to keep up with the increasing complexity of the cementitious materials. In addition, some new construction materials (e.g., 3D Printing material and new industrial waste) have been widely investigated but their microstructures are still poorly presented.

This special issue gathers six papers and aims at providing the fundamental innovations in the development of new technologies to investigate the microstructure and to enhance the performance of traditional Portland or alternative cementitious materials.

\section{OVERVIEW OF THIS SPECIAL ISSUE}

Accepted: 12 March 2021

Published: 06 April 2021

Citation:

Wang L, Chen E, Ruan S and Tang S (2021) Editorial: New Technologies for Investigating Microstructures and

Enhancing Performance of Cementitious Materials.

Front. Mater. 8:669862

doi: 10.3389/fmats.2021.669862
To investigate the hydration products and the microstructure of 3D Printing cementitious materials (3DPC) containing nano- $\mathrm{CaCO}_{3}$ (NC), Yang et al. used the backscattered electron (BSE) and TG, and found that $\mathrm{NC}$ refined the pore structure of 3DPC due to its filler effects and accelerating effects.

An accurate quantification of periclase in high magnesia Portland cement (HMPC) is vital to evaluate the expansive property of HMPC. In a study conducted by Ma et al., a new technique to quantitatively determine the periclase content in HMPC was estiblished by combining the autoclave test, TG and chemical analysis. According to this study, the technique was of high accuracy. 
Ruan et al. synthesized a foamed alkali-activated glass (FAAG) via the use of milled waste glass and foaming agent in low-temperature. By using thermal conductivity meter and XRD, they characterized the phase formation and thermal conductivity of FAAG. They also proposed that the new FAAG was superior to other commercial products in terms of thermal conductivity, density, strength and $\mathrm{CO}_{2}$ emissions.

To investigate the relationships between the mechanical properties of internally cured concrete containing super absorbent polymer (SAP concrete), the uniaxial mechanical properties of SAP concrete with different internal curing water-cement ratios were studied by Xie et al. They proposed the equations among the splitting tensile strength, compressive strength, and flexural strength of SAP concrete based on the conversion formulas of different strength indexes.

In a study performed by Xiao et al., the bonding behavior between engineered cementitious composite (ECC) and steel bars were determined by direct pull-out tests. They demonstrated that failure modes between ECC and steel bars were mainly pull-out failure. Besides, they found that the bond strength increased with fiber content.

$\mathrm{MgO}$ expansive agent can be used in dam concrete to prevent the temperature cracking. In Chen et al.'s study, the autogenous deformation of $\mathrm{MgO}$-admixed concrete with different specimen sizes up to 6 years were investigated. The MIP results confirmed that the pore structure became finer with increasing hydration age and the expansion caused by $\mathrm{MgO}$ hydration would not damage the concrete structures.

\section{CONCLUSIONS}

In this special issue, six papers were collected about the new technologies for investigating cementitious materials and

\section{REFERENCES}

Hou, W., Liu, Z. Q., Huang, J., Yuan, Q., and He, F. Q. (2020). Determination of sulfate content in OPC and CSA cement by sodium carbonate extraction method. Constr. Build. Mater. 274:122056. doi: 10.1016/j.conbuildmat.2020.122056

Li, K., Wang, Y. S., Wang, X., and Zhang, A. M. (2021). Superhydrophobic magnesium oxychloride cement based composites with integral stability and recyclability. Cement. Concrete Comp. 118:103973. doi: 10.1016/j.cemconcomp.2021.103973

Lv, X. D., Dong, Y., Wang, R. K., and Lu, C. (2020). Resistance improvement of cement mortar containing silica fume to external sulfate attacks at normal temperature. Constr. Build. Mater. 258:119630. doi: 10.1016/j.conbuildmat.2020.119630

Lv, X. D., Lin, Y. Q., Chen, X., and Shi, Y. (2021). Environmental impact, durability performance, and interfacial transition zone of iron ore tailings utilized as dam concrete aggregates. J. Clean. Prod. 292:126068. doi: 10.1016/j.jclepro.2021.126068

Ruan, S., and Unluer, C. (2017). Influence of mix design on the carbonation, mechanical properties and microstructure of reactive $\mathrm{MgO}$ cement-based concrete. Cement. Concrte Compos. 80, 104-114. doi: 10.1016/j.cemconcomp.2017.03.004

Wang, L., Guo, F. X., and Tang, S. W. (2020). Comparison between the effects of phosphorous slag and fly ash on the C-S-H structure, long-term hydration heat and volume deformation of cement-based materials. Constr. Build. Mater. 250:118807. doi: 10.1016/j.conbuildmat.2020.118807 enhancing performance. They are the state-of the-art researches, aiming at providing information on the advances of these new technologies. The technologies probing other construction materials such as the metal and ceramic materials are beyond the scope of this special issue.

\section{AUTHOR CONTRIBUTIONS}

LW: writing-original draft and preparation. EC: review. SR: editing. ST: review and supervision. All authors contributed to the article and approved the submitted version.

\section{FUNDING}

The guest editor would like to thank National Key R\&D Program of China (No. 2017YFB0310005), Jiangsu Province Natural Science Foundation (No. BK20181187), Opening Project of State Key Laboratory of Green Building Materials (Nos. 2019GBM05 and 2020GBM07), the Opening Funds of State Key Laboratory of Building Safety and Built Environment and National Engineering Research Center of Building Technology(BSBE2020-2), The Belt and Road Special Foundation of the State Key Laboratory of Hydrology-Water Resources and Hydraulic Engineering (2020492311), Open funding of National Dam Safety Research Center (CX2019B12), and Natural Science Research Project of Shaanxi Provincial Department of Education (20JK0722) for supporting this series of studies.

\section{ACKNOWLEDGMENTS}

The guest editor would like to acknowledge the authors for their inspiring contributions to this special issue.

Wang, L., Guo, F. X., Yang, H. M., Wang, Y., and Tang, S. W. (2021b). Comparison of fly ash, PVA fiber, $\mathrm{MgO}$ and shrinkage-reducing admixture on the frost resistance of face slab concrete via pore structural and fractal analysis. Fractals 29:2140002. doi: 10.1142/S0218348X21 400028

Wang, L., He, T. S., Zhou, Y. X., and Tang, S. W. (2021a). The influence of fiber type and length on the cracking resistance, durability and pore structure of face slab concrete. Constr. Build. Mater. 282:122706. doi: 10.1016/j.conbuildmat.2021.122706

Wang, L., Jin, M. M., Wu, Y. H., Zhou, Y. X., and Tang, S. W. (2021c). Hydration, shrinkage, pore structure and fractal dimension of silica fume modified low heat Portland cement-based materials. Constr. Build. Mater. 272:121952. doi: 10.1016/j.conbuildmat.2020. 121952

Conflict of Interest: The authors declare that the research was conducted in the absence of any commercial or financial relationships that could be construed as a potential conflict of interest.

Copyright (c) 2021 Wang, Chen, Ruan and Tang. This is an open-access article distributed under the terms of the Creative Commons Attribution License (CC BY). The use, distribution or reproduction in other forums is permitted, provided the original author(s) and the copyright owner(s) are credited and that the original publication in this journal is cited, in accordance with accepted academic practice. No use, distribution or reproduction is permitted which does not comply with these terms. 